\title{
Repetition Priming of Motoneuronal Activity in a Small Motor Network: Intercellular and Intracellular Signaling
}

\author{
Allyson K. Friedman and Klaudiusz R. Weiss \\ Department of Neuroscience, Mount Sinai School of Medicine, New York, New York 10029
}

\begin{abstract}
The characteristics of central pattern generator (CPG) outputs are subject to extensive modulation. Previous studies of neuromodulation largely focused on immediate actions of neuromodulators, i.e., actions that were exerted at the time when either neuromodulators were present or neuromodulatory inputs to the CPG were active. However, neuromodulatory actions are known to persist when neuromodulators are no longer present. In Aplysia, stimulation of cerebral-buccal interneuron-2 (CBI-2), which activates the feeding CPG, produces a repetition priming of motor programs. This priming is reflected in an increase of firing of motoneurons. As CBI-2 contains two neuromodulatory peptides, FCAP (feeding circuit-activating peptide) and CP2 (cerebral peptide 2), we hypothesized that repetition priming may involve persistent peptidergic neuromodulation. We find that these peptides produce priming-like effects, i.e., they increase the firing of radula-opening (B48) and radula-closing (B8) motoneurons during motor programs. Proekt et al. (2004, 2007) showed that repetition priming of neuron $\mathrm{B} 8$ is implemented by modulatory inputs that $\mathrm{B} 8$ receives from the CPG. In contrast, our current findings indicate that priming of B48 may be implemented by a direct peptidergic modulation of its intrinsic characteristics via a pathway that activates cAMP. We suggest that the direct versus indirect, i.e., CPG-dependent, repetition priming may be related to the type of input that individual motoneurons receive from the CPG. We suggest that in motoneurons that are driven by concurrent excitation-inhibition, repetition priming is indirect as it is preferentially implemented via modulation of the output of CPGs. In contrast, in motoneurons that are driven by alternating excitation-inhibition, direct modulation of motoneurons may be preferentially used.
\end{abstract}

\section{Introduction}

Characteristics of the outputs of vertebrate and invertebrate central pattern generators (CPGs) are sculpted by the presence of neuromodulators (Harris-Warrick and Marder, 1991; Calabrese, 1998; Marder and Thirumalai, 2002; Dickinson, 2006). Importantly, the effects of neuromodulators often persist when they are no longer present. One could therefore hypothesize that modulation of CPG outputs may persist when neuromodulators are no longer present (Marder et al., 1996). Consistent with this idea, repetitive stimulation of peptide-containing neurons (Morgan et al., 2000; Koh et al., 2003) that activate the feeding CPG of Aplysia results in repetition priming, i.e., a persistent improvement of the articulation of feeding responses that is expressed as an increase of the firing of specific motoneurons (Proekt and Weiss, 2003; Proekt et al., 2004). This priming could result from a persistent upmodulation of motoneuronal firing or, alternatively, from upmodulation of the synaptic drive that motoneurons receive from CPG elements. Previous work (Jing and Weiss, 2002; Proekt et al., 2004, 2007) indicates that modulation of the synaptic drive from $\mathrm{CPG}$ interneurons plays an important role in repetition priming of firing of some, but not all, motoneurons. We analyze

Received March 12, 2010; accepted April 15, 2010.

This work was supported by National Institutes of Health (NIH) Grant NS066587. Some of the Aplysia were provided by the National Resource for Aplysia of the University of Miami under NIH National Center for Research Resources Grant RR0294. We thank Michael R. Due for his valuable comments on this manuscript.

Correspondence should be addressed to Klaudiusz R. Weiss, Box 1065, Department of Neuroscience, Mount Sinai School of Medicine, New York, NY 10029. E-mail: Klaudiusz.weiss@mssm.edu.

DOI:10.1523/JNEUROSCI.1287-10.2010

Copyright $\odot 2010$ the authors $\quad 0270-6474 / 10 / 308906-14 \$ 15.00 / 0$ repetition priming of a specific motoneuron and find that its priming involves a direct, i.e., CPG-independent, modulation of its intrinsic properties. We suggest that direct modulation rather than indirect control of synaptic drive to motoneurons may be related to the particular means that CPGs use to drive specific motoneurons.

Here, we study repetition priming of motoneuron B48. B48 increases its firing rate when motor programs are elicited by a repetitive stimulation of the command-like neuron for feeding cerebral-buccal interneuron-2 (CBI-2) (Friedman et al., 2009). Given that CBI-2 contains two neuromodulatory peptides (Morgan et al., 2000; Koh et al., 2003), it is possible that these peptides mediate repetition priming induced by CBI-2 stimulation. We find that, similar to repetitive stimulation of CBI-2 (Friedman et al., 2009), its peptides increase the firing of $\mathrm{B} 48$ in motor programs. At the cellular level, CBI-2, feeding circuit-activating peptide (FCAP), and cerebral peptide 2 (CP2) increase the firing of B48 in a cAMP-dependent manner. Importantly, in CBI-2elicited motor programs cAMP antagonists block repetition priming of B48, whereas CAMP agonists mimic repetition priming. Thus, our data indicate that repetition priming involves direct peptidergic modulation of the intrinsic properties of B48. This is in contrast to repetition priming of $\mathrm{B} 8$, which is controlled by CPG interneurons B20 and B40 (Proekt et al., 2007).

Control of B48 and B8 firing by the CPG is representative of two major modes of control that are used in a number of CPGs. B48 receives alternating excitation-inhibition that limits B48 firing to one phase of the program. In contrast, B8 firing is controlled by a balance of concurrent inhibition-excitation that B8 
receives in both phases (Jing and Weiss, 2001, 2002; Sasaki et al., 2009). We suggest that direct modulation of firing may be used in a nondisruptive manner in motoneurons driven by alternating excitation-inhibition, but that the same mechanism may be disruptive in motoneurons driven by a balance of concurrent excitation-inhibition.

\section{Materials and Methods}

Animals. Experiments were performed on Aplysia californica obtained from Marinus Scientific. Aplysia were maintained in circulating artificial sea water (ASW) made from Instant Ocean (Aquarium Systems) at $14-15^{\circ} \mathrm{C}$. Animals weighing $150-250 \mathrm{~g}$ were anesthetized by injection of approximately half their weight of isotonic $\mathrm{MgCl}_{2}$ (337 mM).

Electrophysiology. Intracellular recordings were made using singlebarrel electrodes $(6-10 \mathrm{M} \Omega$ ) filled with an electrolyte containing $2 \mathrm{~m} \mathrm{~K}$ acetate and $100 \mathrm{~mm} \mathrm{KCl}$. Intracellular recordings were acquired using either the Axoclamp 2B amplifier (Molecular Devices) or Getting 5A amplifier (Getting Instruments). Extracellular recordings were performed by applying suction electrodes constructed from polyethylene tubing on buccal nerves. Signals were amplified by a CyberAmp 380 (Molecular Devices) and digitized using a Digidata 1200 (Molecular Devices) data acquisition system.

Neuron identification. To identify B48, a semi-intact preparation was used. The cerebral ganglion, buccal ganglia, and the attached buccal mass were dissected out with the cerebral-buccal connectives and buccal nerves intact since they contain the nerves of B48. The buccal mass was separated from the distal digestive system at the buccal-esophageal junction, and a portion of the buccal musculature was cut away to reveal the radula. The cerebral and buccal ganglia were pinned and desheathed in a Sylgard dish with the buccal mass pinned dorsal side down, exposing the radula. The dish was perfused with ASW (in mM: $460 \mathrm{NaCl}, 10 \mathrm{KCl}, 55$ $\mathrm{MgCl}_{2}, 11 \mathrm{CaCl}_{2}$, and 10 HEPES buffer, $\mathrm{pH}$ 7.6) for $1 \mathrm{~h}$. Motoneuron B48 was identified by its location within the ganglion and the distinct radulaopening movements elicited by its intracellular stimulation (Church and Lloyd, 1994; Evans et al., 1996, 1999; Orekhova et al., 2001; Zhurov et al., 2005).

The cerebral and buccal ganglia were then transferred to a recording chamber with a volume of $\sim 1.5 \mathrm{ml}$ of ASW. The preparations was continuously perfused with ASW at $0.3 \mathrm{ml} / \mathrm{min}$ and maintained at $14-17^{\circ} \mathrm{C}$ for $1 \mathrm{~h}$ before beginning experiments. Previously identified neurons CBI-2 and B8 were identified based on location, size, and electrophysiological and morphological characteristics (Rosen et al., 1991; Church and Lloyd, 1994).

Classification of feeding motor programs in Aplysia. During the consummatory phase of feeding, Aplysia produces behaviors that can be ingestive, intermediate, or egestive (Kupfermann, 1974; Morton and Chiel, 1993a,b; Morgan et al., 2002). In all three types of behavior, the animals first protract and then retract their food-grasping organ the radula. During ingestive behaviors, to pull food in, the radula closes in the retraction phase and opens in the protraction phase (Morton and Chiel, 1993a,b). During egestive behaviors, to push material out, the radula closes during protraction and opens during retraction. Ingestive and egestive behaviors can be distinguished using extracellular recordings obtained in vivo by differences in coordination between the activity of the radula-closing motoneuron $\mathrm{B} 8$ and the activity of neurons that produce radula protraction and retraction (Morton and Chiel, 1993a,b; Lum et al., 2005; Zhurov et al., 2005).

Neurons that form the CPG for feeding behaviors are located in the buccal ganglion (Susswein and Byrne, 1988; Teyke et al., 1993; Hurwitz and Susswein, 1996; Hurwitz et al., 1997; Kabotyanski et al., 1998; Jing and Weiss, 2001, 2002; Cropper et al., 2004). In vitro, this feeding CPG is capable of producing coordinated patterns of activity referred to as "fictive feeding motor programs." Although not identical, these in vitro elicited motor programs share essential characteristics with patterns of activity recorded in vivo. Because the phasing of the activity of neuron B8 relative to protraction-retraction can be identified both in vivo and in vitro, B8 activity is used as a frame of reference for defining different types of motor programs. Specifically, during ingestive motor programs the radula closer motoneuron $\mathrm{B} 8$ is predominantly active in the retraction phase, whereas during egestive motor programs B8 is predominantly active in the protraction phase (Jing and Weiss, 2001, 2002; Morgan et al., 2002; Proekt et al., 2004; Jing et al., 2007; Friedman et al., 2009). Based on previous findings, we define the protraction phase as the period of time during which activity is recorded in the I2 nerve (Hurwitz et al., 1996; Nargeot et al., 1999a,b; Jing and Weiss, 2001, 2002; Morgan et al., 2002; Vilim et al., 2010). The retraction phase is defined as the period of time during which high-frequency activity is recorded in the buccal nerve 2 after the end of activity recorded in the I2 nerve (Morton and Chiel, 1993a,b; Nargeot et al., 1999a; Sasaki et al., 2007; Wu et al., 2007; Sasaki et al., 2008, 2009).

We used a plot of B8 retraction versus B8 protraction phase activity along with the previously described classification scheme to operationally assign motor programs to the ingestive, egestive, or intermediate category (Morgan et al., 2002; Proekt et al., 2004, 2007) (Fig. 1C). The approximate boundaries of the ingestive and egestive clusters are shown as defined previously by the phasing of activity of B8 (Morgan et al., 2002). The intermediate programs are those that are outside the boundaries that define the ingestive and egestive programs. With repeated short interstimulus interval (S-ISI) stimulation of CBI-2, programs migrate from intermediate (Fig. 1C) toward ingestive as manifested by the increase in B8 firing frequency during retraction. Representative recordings of the 1st and the 10th programs elicited in this manner are shown in Figure $1 \mathrm{~A}$. Since the radula-opening motoneuron B48 is the focus of the current study, changes in its activity that are associated with the transition of B8 activity-defined intermediate programs to ingestive ones are also illustrated in Figure $1 A, D$. Firing frequencies of B8 and B48 during repeated S-ISI CBI-2 programs were plotted from data obtained from experiments illustrated in Figure 9. For the purpose of data analysis, activity of individual neurons is expressed in terms of their mean firing frequency within a given phase of the program.

Motor program generation. Motor programs were elicited via stimulation of the command-like neuron CBI-2 (Rosen et al., 1991). CBI-2 is activated when food contacts the mouth area. CBI-2 stimulation can elicit reliable motor programs in both semi-intact preparations and reduced preparations (Jing and Weiss, 2002, 2005; Morgan et al., 2002; Proekt et al., 2004; Sasaki et al., 2008). CBI-2 was stimulated by repetitive depolarizing $(8-9 \mathrm{~Hz})$ current pulses, each of which triggered a single action potential. CBI-2 stimulation was manually terminated after the end of the protraction phase, as determined by the termination of activity in the protraction motoneuron-containing I2 nerve (I2N) (Hurwitz et al., 1996, 2000). Two different CBI-2 stimulation paradigms were used. CBI-2 programs were elicited using either an S-ISI of $30 \mathrm{~s}$, in which CBI-2 was stimulated to elicit a program $30 \mathrm{~s}$ after the end of retraction of the previous program, or a long interstimulus interval (L-ISI), in which CBI-2 was stimulated to elicit a program $3 \mathrm{~min}$ after the end of retraction of the previous program.

Reagents. FCAP (SynPep) (Sweedler et al., 2002) and CP2 (SynPep) (Phares et al., 1996; Vilim et al., 2001) were perfused at $10^{-6} \mathrm{M}$, a concentration that produces maximum effects (Koh et al., 2003). In all experiments, peptides were perfused at a rate of $0.3 \mathrm{ml} / \mathrm{min}$. For intracellular injections, a $10 \mathrm{~mm}$ concentration of 8-bromo-cAMP (8-brcAMP) was used (Sigma). An $80 \mathrm{~mm}$ concentration of the Rp isomer of cAMP (Rp-cAMP) was used for intracellular injections (Sigma). Both 8-br-cAMP and Rp-cAMP were first dissolved in dimethyl sulfoxide (DMSO). The final concentration of DMSO in the electrode never exceeded $0.75 \%$. Both 8-br-cAMP and Rp-cAMP were iontophoresed with a single-barrel electrode using $10 \mathrm{~ms}$ hyperpolarizing current pulses every 10 s. A $0.2 \%$ DMSO solution of buffered distilled water (HEPES 10 $\mathrm{mM}, \mathrm{pH}$ 7.6) was injected to probe for the potential effects of DMSO. The size of the current pulses was adjusted so that they produced $\sim 10 \mathrm{mV}$ hyperpolarization. A high-divalent ASW was perfused to suppress polysynaptic responses and spontaneous activity during measurements of firing during depolarization and occlusion experiments (in mм: 368 $\mathrm{NaCl}, 10 \mathrm{KCl}, 101 \mathrm{MgCl}_{2}, 13.8 \mathrm{CaCl}_{2}$, and 10 HEPES, pH 7.6) (Trudeau and Castellucci, 1992).

Statistics. Digitized electrophysiological recordings were plotted using CorelDRAW v. 13 (Corel), and data were expressed as the mean \pm SEM. 
Two-group statistical comparisons were performed using $t$ test statistics. Multigroup data were analyzed using ANOVA, and subsequent comparisons were performed using Bonferroni's multiple-comparison tests. The significance level was set at $p<0.05\left({ }^{* *} p<\right.$ $0.001 ;{ }^{* *} p<0.01$; ${ }^{*} p<0.05$; n.s., $\left.p>0.05\right)$. All statistical tests were performed using SigmaPlot (Systat Software).

\section{Results}

\section{Peptides and repetition priming}

There are two major ways in which activity of the feeding CPG is affected by the command-like neuron CBI-2. First, acting with fast dynamics CBI-2 triggers motor programs. Second, acting with slow dynamics repeated stimulation of CBI-2 modifies these programs so that they evolve from intermediate-type programs to ingestive ones. CBI-2 triggers motor programs using fast cholinergic transmission (Hurwitz et al., 2003). In addition to ACh, two neuropeptides, FCAP and CP2 (Phares et al., 1996; Sweedler et al., 2002), are present in CBI-2 (Morgan et al., 2000; Koh et al., 2003). Given that stimulation paradigms that produce repetition priming have been shown to be favorable for peptide release in Aplysia (Whim and Lloyd, 1989, 1990; Cropper et al., 1990; Vilim et al., 1996b, 2000; Brezina et al., 2000b), we reasoned that these peptides may be involved in repetition priming, i.e., an enhancement of motoneuronal firing when motor programs are elicited by repetitive CBI-2 stimulation.

As a first step toward exploring the possible involvement of peptides in the evolution of programs from intermediate to ingestive, we sought to determine whether perfusion of the peptides contained in CBI-2 (CP2 and FCAP) would mimic the effects of repetitive stimulation of CBI-2, i.e., whether it would convert intermediate programs elicited by CBI- 2 into ingestive ones. To prevent the motor programs from becoming ingestive, as a result of repetitive stimulation of CBI-2, we stimulated CBI-2 using an L-ISI ( $3 \mathrm{~min}$ ). Importantly, consistent with the definition of intermediate programs (see Materials and Methods), under these conditions of stimulation B8 fires at low frequencies during both the retraction and the protraction phase.

Perfusion of FCAP/CP2 dramatically altered the character of motor programs, as exemplified in a recording from a single preparation (Fig. 2, compare A1, A2). Comparison of Figure $2 A 1$ and $A 2$ indicated that in terms of $B 8$ activity, motor programs became ingestive as the firing pattern of $\mathrm{B} 8$ changed from one in which B8 fired at a low frequency throughout the retraction and protraction phase, to the pattern in which B8 fired at a high frequency during retraction while maintaining a relatively low firing rate during protraction. Note that this was associated with an increased firing of B48 during protraction. The effects of peptides were reversed with washout.

Quantitative analyses of the aggregate data showed that indeed the changes illustrated in Figure $2 A$ were statistically signif-
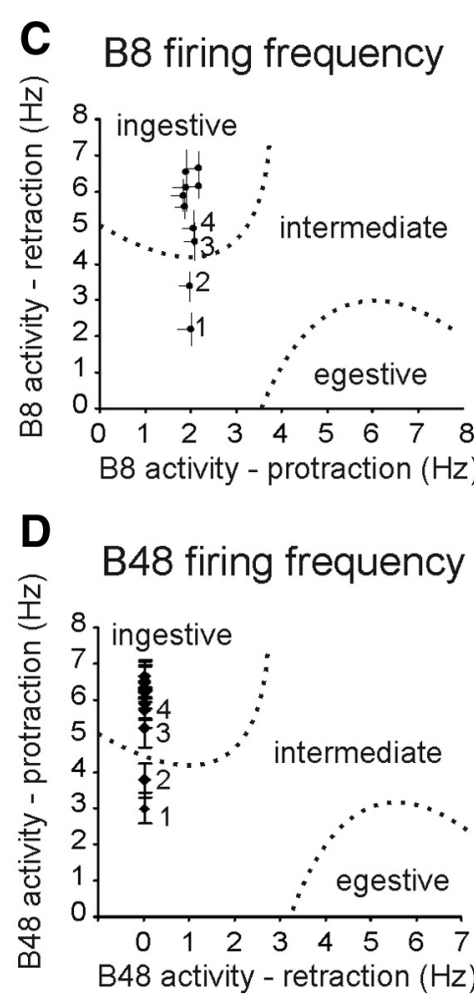

Figure 1. Activity of motoneurons B48 and B8 during S-ISI CBI-2-elicited motor programs. $A$, Shown are the 1st and the 10th motor program that were elicited by $\mathrm{CBI}-2$ stimulation. The black bars mark the protraction phase, and the white bars mark the tion phase. A series of $10 \mathrm{CBI}-2$ programs were elicited 30 s apart. Repeated $\mathrm{CBI}-2$ stimulation elicited a progressive increas organization and localization of CPG neurons involved in the control of motoneurons B48 and B8. Large and small triangles denote small and large excitatory connections, respectively. Black circles denote inhibitory connections. Zigzags denote electrical coupling. Low-frequency firing is denoted by gray outline. Neurons are shown in the left or right part of the diagram depending on whether they are active in the protraction or the retraction phase, respectively. B8 is shown in both parts of the diagram because it fires in program. B40 fires at high frequency during the protraction phase, promoting B8 firing in the retraction a series of protraction-phase interneurons and motoneurons, and fires exclusively in the protraction phase. C, Plot of B8 activity during versus B activity during retraction illustrates cluster boundaries for ingestive and egestive motor programs. Ulation of $\mathrm{CBI}-2$, B8 firing frequency increases during retraction, and motor programs migrate toward the ingestive cluster. $D, P l o t$ of B48 activity during retraction versus B48 activity during protraction. With repeated stimulation of $\mathrm{CBI}-2, \mathrm{~B} 48$ firing frequency increases during protraction, and motor programs migrate toward the ingestive cluster.

icant. Specifically, we performed a one-way ANOVA of B8 firing frequency during protraction phase $\left(F_{(2,6)}=3.95 ; p=0.08, n=\right.$ $4)$ and retraction phase $\left(F_{(2,6)}=189.64, p<0.001, n=4\right)$. Individual comparisons of firing frequency revealed that after a 10 min perfusion of peptides, retraction-phase firing of B8 was significantly higher compared with controls and washout conditions (control vs FCAP/CP2: $t=15.88, p<0.001$; FCAP/CP2 vs washout: $t=17.70, p<0.001)$. In contrast, peptides did not affect the frequency of $\mathrm{B} 8$ firing during protraction (control vs FCAP/CP2: $t=2.25, p=0.20$; FCAP/CP2 vs washout: $t=2.58$, $p=0.20)$. Together, these data indicated that, as defined by $\mathrm{B} 8$ activity, perfusion of peptides converted the motor programs to ingestive ones, thus mimicking the effect of repetitive stimulation of CBI-2.

In addition to increasing the retraction-phase firing of B8, repetitive stimulation of $\mathrm{CBI}-2$ increased the frequency of protraction-phase and post-retraction-phase firing of B48 (Friedman et al., 2009). Furthermore, repetitive stimulation of CBI-2 also shortened the latency from the beginning of CBI-2 stimulation to the first B48 action potential. Consistent with the shortening of 
A1

\section{Control}

L-ISI CBI-2 elicited intermediate program

B48

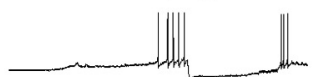

B8

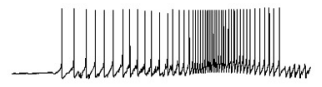

$12 \mathrm{n}$

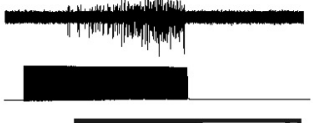

CBI-2

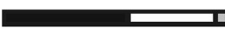

$B$
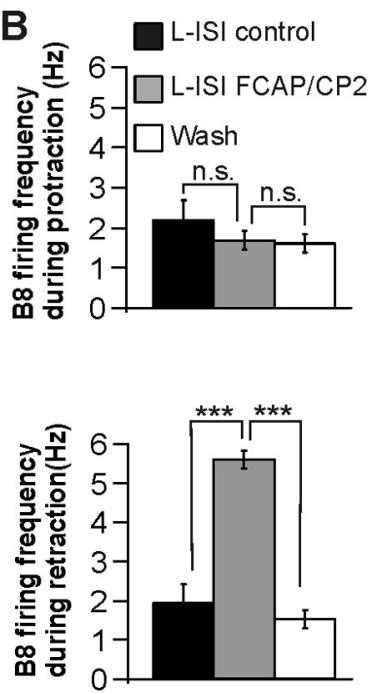

A2

FCAP \& CP 2

L-ISI CBI-2 elicited ingestive program
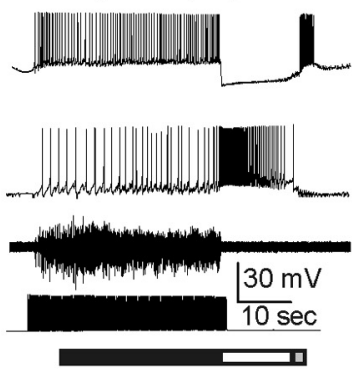

C
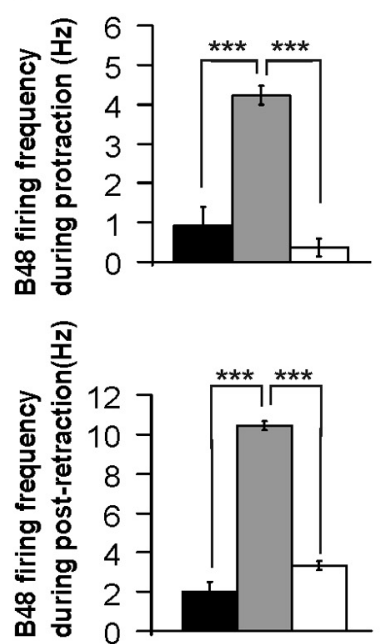

D

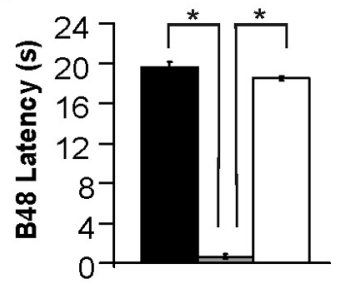

A3

Wash

L-ISI CBI-2 elicited program after wash
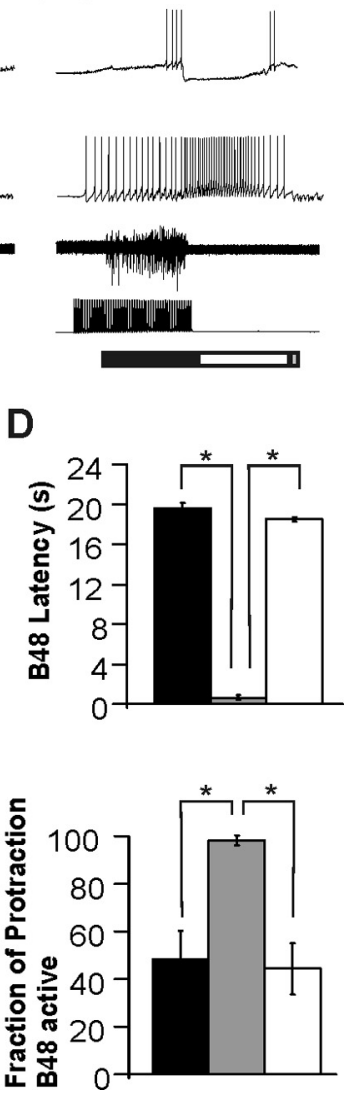

Figure 2. Effect of exogenous FCAP and CP2 on L-ISI CBI-2-elicited programs. Black and white bars indicate the protraction and retraction phases, respectively. A series of five CBI-2 programs was elicited every $3 \mathrm{~min}$ (L-ISI) (control) that generated intermediate programs. FCAP and CP2 were then superfused during the L-ISI CBI-2-elicited programs (FCAP and CP2). $A$ 1, Representative recordings of L-ISI CBI-2-elicited intermediate program in which $B 48$ fires weakly in the protraction phase. A2, L-ISI CBI-2-elicited program in the presence of FCAP and CP2 in which B48 fired robustly during the protraction phase and B8 fired robustly during the retraction phase. A3, L-ISI CBI-2-elicited program after 15 min of washout in which B48 protraction activity and $B 8$ retraction activity were weak. $B$, Aggregate data of the effects of FCAP and CP2 on L-ISI CBI-2-elicited programs on B48 protraction and postretraction firing frequency. $C$, Aggregate data of the effects of FCAP and CP2 on L-ISI CBI-2-elicited programs on B8 protraction and retraction firing frequency. $\boldsymbol{D}$, Aggregate data show that there was a significantly shorter B48 latency and a significantly higher fraction of protraction with B48 activity in the presence of FCAP and CP2.

the latency, the fraction of the protraction phase during which B48 fires also increased. We analyzed the effects FCAP/CP2 on all of these parameters of B48 firing. We performed a one-way ANOVA of B48 firing frequency in the protraction phase and found that there was an overall significant difference between conditions $\left(F_{(2,6)}=41.48, p<0.001, n=4\right)$. The differences in the post-retraction-phase firing were also statistically significant $\left(F_{(2,6)}=49.52, p<0.001, n=4\right)$. Individual comparisons revealed that there was a significant increase in B48 firing in the presence of FCAP/CP2 compared with control or washout conditions (protraction: control vs FCAP/CP2: $t=7.23, p<0.001$; FCAP/CP2 vs washout: $t=8.41, p<0.001$; post-retraction: control vs FCAP/CP2: $t=9.25, p<0.001$; FCAP/CP2 vs washout: $t=$ $7.80, p<0.001)$. Further analysis of B48 activity during protraction phase revealed that the latency from the onset of CBI-2 stimulation to the first action potential in B48 decreased significantly from $19.6 \pm 5.9$ to $0.63 \pm 0.20 \mathrm{~s}$ in the presence of peptides $(t=$ $4.26, p<0.05$ ). Consistent with this observation, we found that the fraction of the protraction phase in which $\mathrm{B} 48$ was active also increased significantly $(t=5.08, p<0.05)$ during superfusion of FCAP/CP2.

Together, the data shown in Figure 2 indicated that $\mathrm{B} 48$ protraction and $\mathrm{B} 8$ retraction activity was upregulated by FCAP/CP2, resulting in an increase of ingestiveness of motor programs. Perfusion of these peptides, FCAP/CP2, reproduces all of the previously reported effects of a repetitive CBI-2 stimulation on B48 and B8 firing frequencies during protraction and retraction phases (Friedman et al., 2009).

\section{B48: effects of peptides and CBI-2 stimulation}

In networks that are characterized by a significant degree of interconnectivity, modulation of the intrinsic properties of individual neurons may appear to be the simplest way of selectively regulating the firing frequency of individual neurons. Although it did not have to be so, this mechanism of regulation appeared plausible in the case of neuron B48, which receives its excitatory input and fires during protraction but is inhibited during retraction. Thus, upmodulation of B48 firing by CBI-2 or peptides would not result in a nonspecific firing of B48 during both protraction and retraction phases. In contrast, B8 receives its mixed excitatoryinhibitory input during both protraction and retraction, and fires, albeit to a different degree, in both the protraction and retraction phases in different types of motor programs. Therefore, upmodulation of B8 firing would likely result in an overall increase of B8 activity. This is not what was observed either with repetitive CBI-2 stimulation (Proekt et al., 2004) or with FCAP/CP2 perfusion (Fig. 2). Therefore, it is unlikely that modulation of B8 intrinsic properties would be used to modify the firing of $\mathrm{B} 8$ in response to stimulation of CBI-2 or FCAP/CP2 perfusion.

We thus sought to determine whether both stimulation of CBI-2 and perfusion of FCAP/CP2 differentially altered the number of action potentials elicited by a depolarizing input to B48 and $\mathrm{B} 8$. Action potentials were elicited in B48 and B8 using injections of a $3 \mathrm{~s}$ constant depolarizing current pulse every 60 s. Current size in individual experiments was selected to generate $\sim 10$ action potentials under control conditions. The preparations were superfused with a high-divalent ASW to reduce spontaneous activity and polysynaptic effects. We compared the number of action potentials before and after a $10 \mathrm{~s}$ stimulation of CBI-2 at 9 Hz. After CBI-2 stimulation, the number of B8 action potentials did not change (Fig. $3 B$ ), but the number of $B 48$ action potentials increased from $10.0 \pm 1.2$ to $23.8 \pm 3.5$ (Fig. $3 A$ ) and then gradually returned to control levels. A one-way repeated-measures ANOVA on the number of action potentials elicited during control, 1 min after CBI-2 stimulation, and after a 25 min recovery showed that for B48 there was an overall significant difference 
between these conditions $\left(F_{(2,8)}=18.80\right.$, $p<0.01, n=5)$. No such difference was detected for $\mathrm{B} 8\left(F_{(2,8)}=0.23, p=0.79, n=\right.$ $5)$. Individual comparisons revealed that B48 fired at a significantly higher frequency $1 \mathrm{~min}$ after CBI-2 stimulation (pre-CBI-2 stimulation vs 1 min postCBI-2: $t=5.3, p<0.01 ; 1 \mathrm{~min}$ post-CBI-2 vs recovery: $t=5.3, p<0.01)$. After CBI-2 stimulation, there was also a significant decrease in the latency to the first B48 action potential elicited during the same size depolarization (from $36.10 \pm 1.31$ to $93.26 \pm 2.76 \mathrm{~ms})(t=19.12, p<0.001$, $n=5)$. After CBI-2 stimulation, the resting membrane potential became significantly more positive (from $-58.88 \pm 3.14$ to $-55.92 \pm 2.92 \mathrm{mV})(t=3.65, p<0.05$, $n=5)$.

To further characterize the effects of CBI-2 stimulation on B48, we characterized the depolarization required to elicit action potentials before and after CBI-2 stimulation. Two electrodes were used, one to inject a series of increasing depolarizing current pulses ( $1.0 \mathrm{nA}$ increments; 2 s duration) and a second to record the resulting voltage deflection. Before the injection of the current pulses, the membrane potential of B48 was adjusted to $-80 \mathrm{mV}$. A series of progressively larger current pulses was injected into B48 $(n=5)$. After 10 s of CBI-2 stimulation, an identical series of current pulses produced a significantly larger depolarization (Fig. 3C, depolarization post-CBI-2 is underlined). The $5 \mathrm{nA}$ current pulses after CBI-2 stimulation elicited a larger depolarization $(22.68 \pm 0.60$ vs $18.36 \pm 0.71 \mathrm{mV}: t=5.81, p<0.01, n=5)$. The representative traces also illustrated a significant decrease in spike threshold from $-43.25 \pm 3.73$ to $-50.61 \pm 3.35 \mathrm{mV}(t=$ 7.40, $p<0.01, n=5$ ) (Fig. 3C). These increases could be expected to enhance B48 firing in motor programs and thus endow the programs with more ingestive-like characteristics.

Next, we sought to determine whether perfusion of FCAP and CP2 mimicked the effects CBI-2 stimulation on B48 and B8 firing as would be predicted if the effects of the stimulation of CBI-2 were to be mediated by the FCAP/CP2 peptides. The stimulation parameters were the same as described above. We found, as illustrated in recordings from a single preparation (Fig. 4A1) and from aggregate data (Fig. 4A2), that the perfusion of FCAP and CP2 increased the number of B48 action potentials elicited during a constant current pulse. Not unexpectedly, we found no differences in the number of B8 action potentials elicited during perfusion of FCAP and CP2 (Fig. 4B).

To determine the overall significance level of differences among the number of B48 action potentials elicited during control, at the end of a 5 min perfusion of FCAP, and after 25 min washout, we performed a one-way repeated-measures ANOVA $\left(F_{(2,8)}=24.62, p<0.001, n=5\right)$. Individual comparisons re- vealed that, compared with the control and post-washout period, the number of action potentials elicited in B48 in the presence of FCAP was significantly higher (control vs FCAP: $t=5.92, p<$ 0.001 ; FCAP vs washout: $t=6.21, p<0.001$; control vs washout: $t=0.25, p=1.00)$. In addition, after the perfusion of FCAP, the latency to the first action potential was significantly shorter $(38.92 \pm 4.82$ vs $155.42 \pm 27.53 \mathrm{~ms}: t=4.07, p<0.05, n=5)$. In the presence of FCAP, the resting membrane potential became significantly more positive (from $-55.40 \pm 3.64$ to $-47.0 \pm 2.03$ $\mathrm{mV}: t=2.79, p<0.05, \mathrm{~N}=5)$. Using the same paradigm as above, we measured the number of action potentials elicited before $\mathrm{CP} 2$ perfusion, in the presence of $\mathrm{CP} 2$, and after the washout of $\mathrm{CP} 2$. As illustrated in recordings from a single preparation (Fig. 4B1) and the graph of aggregate data (Fig. 4B2), CP2 superfusion also increased the number of $\mathrm{B} 48$ action potentials. A one-way repeated-measures ANOVA showed that there was an overall significant difference among the three conditions $\left(F_{(2,6)}=\right.$ 20.70, $p<0.01, n=4)$. Individual comparisons showed a significant increase in the number of $\mathrm{B} 48$ action potentials during CP2 
A1

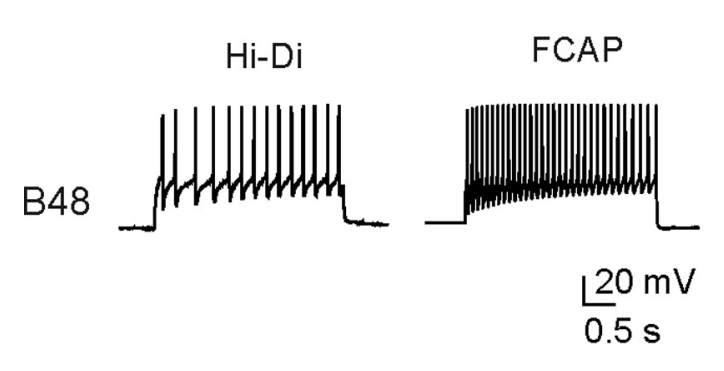

Hi-Di

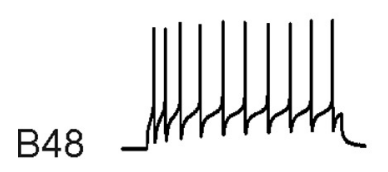

$\mathrm{CP} 2$

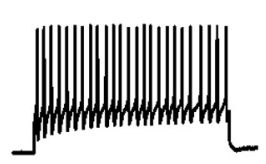

B1
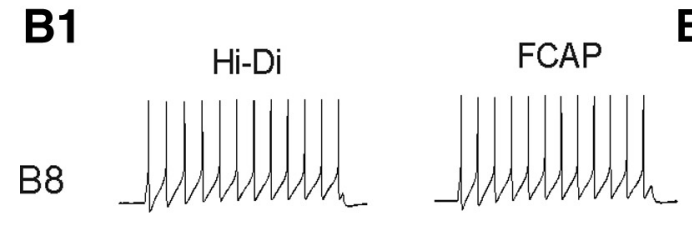

B2.

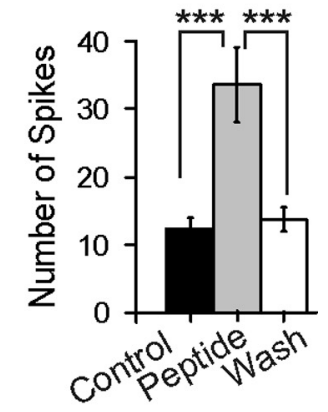

A2

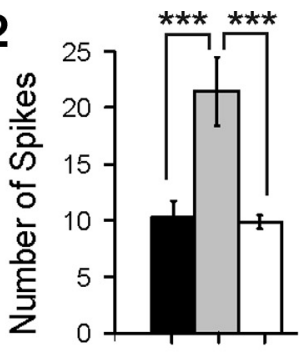

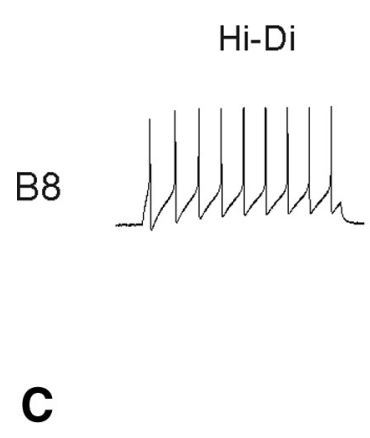

Control
FCAP \& CP 2

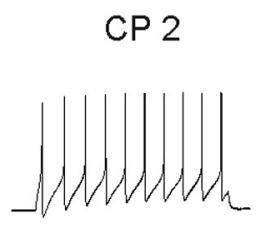

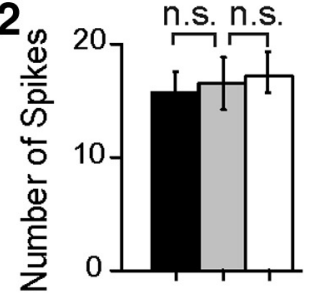
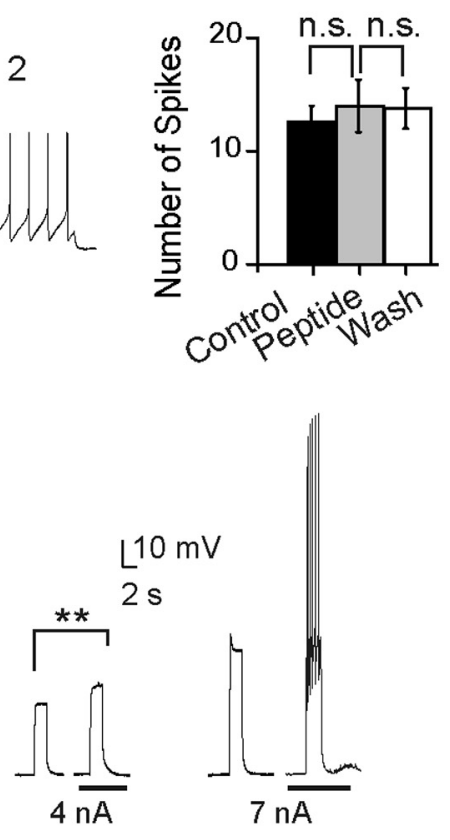

B48 $-80$

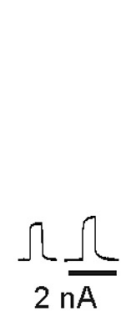

$4 \mathrm{nA}$

Figure 4. $F C A P$ and $C P 2$ increase the number of $B 48$ action potentials, but not the number of $B 8$ action potentials elicited by the same size current pulse. $A$, Representative recordings of $B 48$ firing before and during the presence of FCAP and CP2. A $3 \mathrm{~s}$ current pulse was injected into B48 every $60 \mathrm{~s}$. Aggregate data show a significant increase in B48 action potentials elicited by the same current injection in the presence of FCAP and $C P 2 . B$, Representative recordings of $B 8$ firing before and during the presence of FCAP and CP2. A 3 s current pulse was injected into $B 8$ every $60 \mathrm{~s}$. Aggregate data show no significant change in B8 action potentials elicited by the same current injection in the presence of FCAP and CP2. C, FCAP and CP2 increase the input resistance of $B 48$. B48 membrane potential was held at -80 with a series of $2 \mathrm{~s}$ current injections before and during FCAP and CP2 superfusion (underlined). Note increased depolarization in the presence of peptide compared with the same size current injection.

superfusion compared with control and washout (control vs CP2: $t=5.75, p<0.01$; CP2 vs washout: $t=5.38, p<0.01$; control vs washout: $t=1.34, p=1.00)$. In the presence of $\mathrm{CP} 2$, the latency to the first action potential was also significantly shorter $(38.20 \pm 9.60 \mathrm{vs}$ $146.35 \pm 9.52 \mathrm{~ms}: t=5.73, p<0.05, n=5)$. In the presence of $\mathrm{CP} 2$, the resting membrane potential became significantly more positive (from $-55.62 \pm 6.33$ to $-48.55 \pm 4.60 \mathrm{mV}$ : $t=3.29, p<0.05, n=5)$. Thus, both peptides increased the firing of B48.

Perfusion of either FCAP or CP2 did not alter the number of $\mathrm{B} 8$ action potentials elicited, as illustrated in the representative recording (Fig. 4B1) and aggregate data (Fig. 4B2). A one-way repeatedmeasures ANOVA on the number of action potentials elicited during control, at the end of a 5 min superfusion of FCAP or $\mathrm{CP} 2$, and after a $25 \mathrm{~min}$ washout showed that, indeed, among the three conditions there were no statistically significant differences in the number of spikes elicited in B8 by constant current injections (FCAP: $F_{(2,8)}=0.27, p=0.77, n=5 ; \mathrm{CP} 2: F_{(2,8)}=$ $0.33, p=0.72, n=5)$. Thus, perfusion of either peptide did not alter B8 firing. This lack of modulation of B8 firing was consistent with the previous data showing that B8 firing was controlled by the balance of outputs of premotor neurons that differentially regulate $\mathrm{B} 8$ firing during protraction and retraction (Jing et al., 2003; Proekt et al., 2007).

We next sought to determine whether FCAP and CP2 also mimicked the effects of CBI-2 stimulation on the size of depolarization elicited by current injections. Using the same paradigm as in Figure 3C, we examined the alteration in depolarization size during application of FCAP and CP2 (Fig. 4C, underlined), and in all preparations found that they increased the size of the depolarization to the same size current injection compared with the control conditions (representative recording) (Fig. 4C). The $4 \mathrm{nA}$ current pulses in the presence of FCAP/CP2 elicited a significantly larger depolarization $(30.42 \pm 2.05$ vs $27.62 \pm$ $2.26 \mathrm{mV}: t=9.84, p<0.001, n=5)$. The traces also illustrated a significant decrease in spike threshold from $-42.29 \pm 0.54$ to $-50.01 \pm 0.82 \mathrm{mV}(t=11.792, p<0.001$, $n=5)$. Thus, both brief stimulation of CBI-2 and peptide perfusion increased the firing and increased the size of the depolarization in B48. Since these experiments were conducted in high-divalent ASW, the results were consistent with the idea that intrinsic properties of B48 may be directly modulated by CBI-2 acting through its peptides, FCAP and CP2. 
Because stimulation of both CBI-2 and peptides exerted a similar action on B48, we reasoned that FCAP and CP2 may contribute to the changes in B48 firing observed after CBI-2 stimulation. To explore this possibility, we used an occlusion paradigm (Swensen and Marder, 2000; Koh and Weiss, 2005, 2007) and tested the ability of exogenous peptides to occlude the effects of CBI-2 stimulation on the firing of B48. Again, a high-divalent ASW was used to reduce the threshold for initiation of action potentials, thereby reducing polysynaptic inputs. Current pulses that elicited $\sim 10$ action potentials in B48 were injected every $60 \mathrm{~s}$.

Perfusion of FCAP and CP2 produced an increase in the number of B48 action potentials elicited by the same size constant current injection (representative recording) (Fig. 5A1). To avoid ceiling effects, in the continued presence of FCAP and CP2, the size of the injected current pulse was reduced to again elicit $\sim 10$ action potentials, i.e., approximately the same number of action potentials that current pulses elicited before perfusion of FCAP or CP2. In the continued presence of FCAP and CP2, CBI-2 was then stimulated for $10 \mathrm{~s}$, using the same frequency that previously increased the number of action potentials elicited in B48 (Fig. $3 A$ ). We found there was no significant increase in B48 firing after CBI-2 stimulation in the presence of FCAP and CP2 $(t=1.027, p=0.38, \mathrm{df}=3)$ (Fig. $5 A 2)$. Thus, occlusion by FCAP and CP2 of the ability of CBI-2 stimulation to increase the number of $\mathrm{B} 48$ action potentials suggested convergent actions of peptides FCAP/CP2 and CBI-2 stimulation.

\section{B48: role of cAMP}

If CBI-2 used its peptides to modulate the intrinsic properties of $\mathrm{B} 48$, one would expect that the same intracellular signaling pathway would mediate the effects of CBI-2 stimulation and peptide perfusion. To narrow our search, we first sought to determine whether exogenous application of IBMX, a phosphodiesterase inhibitor, increased the CBI-2-elicited enhancement of B48 firing. Action potentials were elicited in B48 using injections of a $3 \mathrm{~s}$ constant depolarizing current pulse every $60 \mathrm{~s}$. Current size in individual experiments was selected to generate $\sim 10$ action potentials under control conditions. We measured the number of B48 action potentials after a $10 \mathrm{~s}$ CBI-2 stimulation and found that they were significantly potentiated during perfusion of 100 $\mu \mathrm{M} \operatorname{IBMX}(t=4.78, p<0.05, n=4)$. Measurements of the time needed for the increased firing to decline by $66 \%$ from its peak value after the CBI-2-elicited enhancement in the number of B48 action potentials was significantly longer in the presence of IBMX (control, $5.0 \pm 0.58$ vs post-CBI-2, $21.3 \pm 2.03 \mathrm{~m} ; t=6.80, p<$ $0.05)$. This suggested that cyclic nucleotides may act to increase B48 firing and may also contribute to regulation of the duration of this enhancement.

Given that previous work showed that the cAMP/protein kinase A (PKA) pathway is an effective means of regulating neuronal firing in Aplysia, we investigated the role of this pathway (Klein et al., 1986; Ghirardi et al., 1992; Goldsmith and Abrams, 1992). To examine the possibility that the cAMP/PKA pathway mediated the increased number B48 action potentials, we mea- sured changes in the number of action potentials produced by intracellular injections of 8-br-cAMP, an analog of cAMP. In this paradigm, we used three separate electrodes. The first electrode was used to inject a depolarizing $3 \mathrm{~s}$ constant current pulse into B48. Pulse size was adjusted to elicit $\sim 10$ action potentials every 60 s. Simultaneously, a second electrode recorded the resulting depolarization. After a series of these stimulations, a baseline of firing was established. To increase the level of cAMP in B48, using a third electrode we iontophoretically injected 8-br-cAMP (10 $\mathrm{mM}$ ) for $15 \mathrm{~min}$. After injection of 8-br-cAMP and removal of the injecting electrode, using the same size current pulses we measured the number of action potentials elicited in B48. We found that intracellular injection of cAMP analog 8-br-cAMP increased the number of action potentials from $10.8 \pm 0.6$ to $21 \pm 4.2$ (Fig. $6 A$ ) and then gradually returned to control levels. To ensure that the DMSO in which 8-br-cAMP was dissolved did not increase B48 firing, using the same three-electrode paradigm we measured the number of $\mathrm{B} 48$ action potentials after a 15 min injection of a $0.20 \%$ DMSO solution. We found that DMSO injection alone had no significant effect on B48 firing (control, $9.06 \pm 0.24$ vs post-DMSO injection, 9.28 $\pm 0.36 ; t=0.55, p=0.61, n=4)$.

To analyze the increase in the number of action potentials observed after 8-br-cAMP injection, we performed a one-way repeated-measures ANOVA between the number of B48 action potentials elicited during the control preinjection period, after injection of cAMP, and after a $30 \mathrm{~min}$ recovery period (Fig. 6B) $\left(F_{(2,8)}=91.81, p<0.001, n=5\right)$. Individual comparison revealed there was a significant increase in the number of action potentials after injection of 8-br-cAMP (preinjection control vs 8 -br-cAMP injected, $t=12.46, p<0.001 ; 8$-br-cAMP injected vs recovery, $t=10.84, p<0.001)$. Intracellular injections of 8 -brcAMP into B48 mimicked the effects of both FCAP/CP2 and CBI-2 stimulation on the firing of B48, thus implicating the cAMP/PKA pathway as a possible mediator of the FCAP/CP2 and CBI-2 stimulation-induced effects involved in the development of an ingestive program.

Although this demonstrated that cAMP was capable of augmenting the number of B48 action potentials, it remained to be determined whether cAMP was necessary to increase the firing of $\mathrm{B} 48$ in response to $\mathrm{CBI}-2$ stimulation and/or peptide superfu- 
A

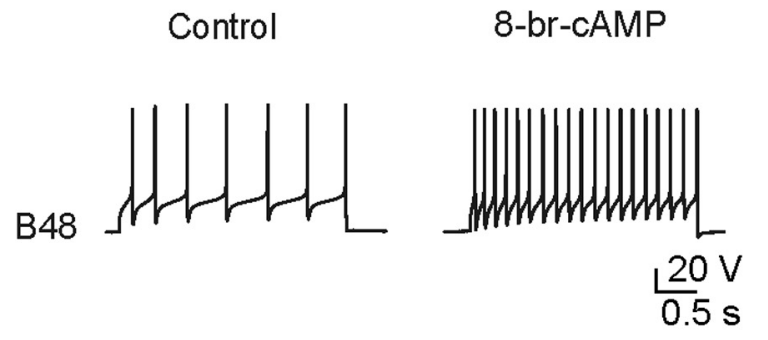

B

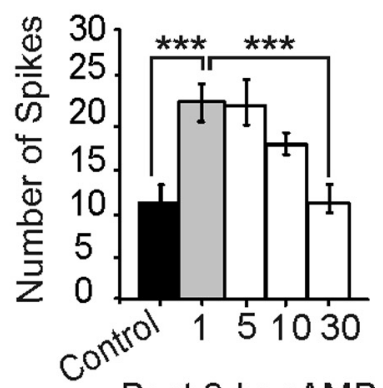

Post 8-br-cAMP injection ( $\mathrm{min})$

Figure 6. Intracellular injection of 8-br-cAMP increases B48 firing. $A$, Representative recordings of B48 firing before and after injection of 8-br-cAMP. Every 60 s, B48 was injected with a constant depolarizing current pulse ( 3 s duration). The change in the number of action potentials generated from the same size current pulse was measured after a 15 min injection with 8-br-cAMP. $\boldsymbol{B}$, Aggregated data show that there is a significant increase in B48 firing 1 min after injection of 8-br-cAMP.
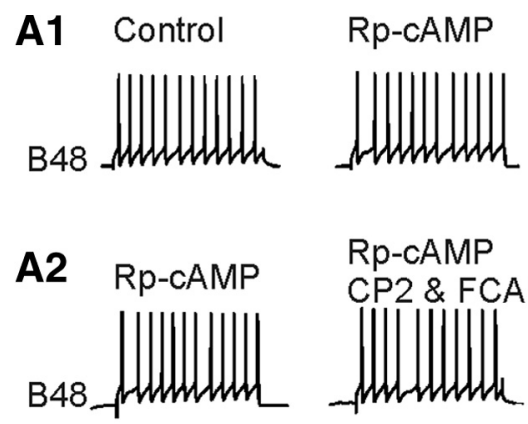

\section{A3}

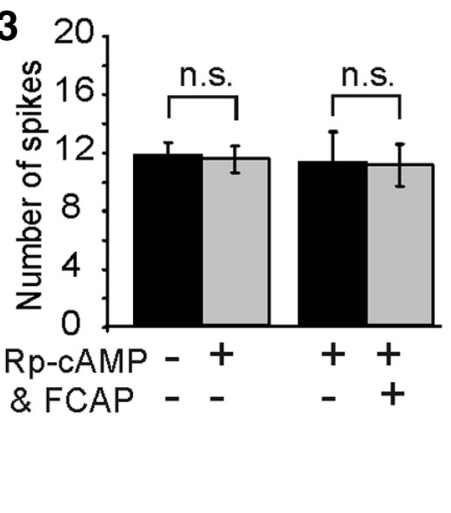

B1

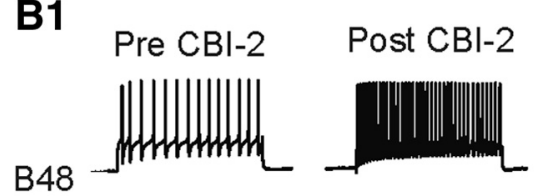

Control

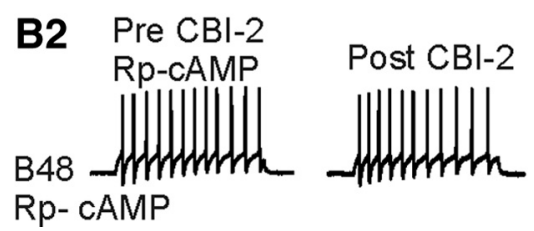

B3

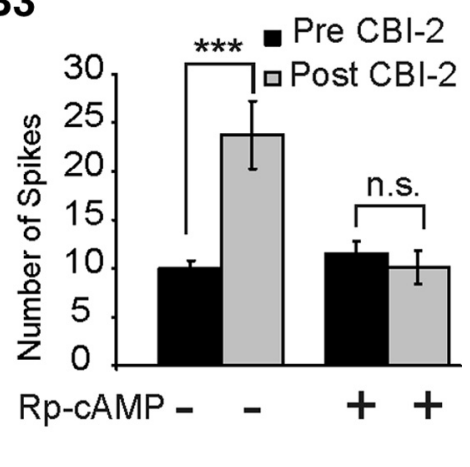

Figure 7. Effects of FCAP/CP2 and $\mathrm{CBI}-2$ stimulation on $\mathrm{B} 48$ firing are blocked after injection of Rp-CAMP. $A 1$, The number of B48 action potentials was not altered by the injection of Rp-CAMP. Representative recordings of $B 48$ firing during $3 \mathrm{~s}$ current injections before and after Rp-CAMP injection are shown. A2, Injection of Rp-CAMP into B48 blocked FCAP- and CP2-induced increases in B48 firing. Representative recordings of Rp-CAMP-injected B48 firing during $3 \mathrm{~s}$ current pulses before and during the application of FCAP and CP2. A3, Aggregate data: average number of B48 action potentials elicited by the same current injection before and after injection of Rp-CAMP and the average number of action potentials in Rp-cAMP injected B48 before and during FCAP and CP2 application. B1, Representative recordings of $3 \mathrm{~s}$ current injections of $B 48$ before and $1 \mathrm{~min}$ after CBI-2 2 stimulation. B2, Representative recording of Rp-cAMP-injected B48 current pulses before and $1 \mathrm{~min}$ after $10 \mathrm{~s}$ (BI-2 stimulation. Rp-cAMP injection into B48 blocked the CBI-2 stimulation-induced increase in firing. $B 3$, Aggregate data: average number of $B 48$ action potentials elicited by the same size current injection before and after CBI-2 stimulation, before and after injection of Rp-cAMP.

sion. To address this issue, we investigated whether the increase in the firing of B48, observed after CBI-2 stimulation and during FCAP/CP2 application, could be eliminated when a competitive antagonist of cAMP activation was injected into B48. Here, we measured the number of action potentials elicited during a constant current depolarization (3 s duration). We first performed experiments to establish that Rp-cAMP, a competitive antagonist of the activation of cAMP-dependent protein kinase, did not alter the control level of the firing of B48. We found that injection of Rp-cAMP did not alter the number of $\mathrm{B} 48$ action potentials (Fig. 7A1) (control vs after injection of Rp-cAMP: $t=0.751, p=0.53, n=5$ ). Using the same stimulation paradigm, we measured the effect of FCAP/CP2 perfusion on the firing of B48 after a $15 \mathrm{~min}$ injection of Rp-cAMP (Fig. 7A2). Analysis of aggregate data showed that, in the presence of the antagonist, FCAP/CP2 did not increase the number of $\mathrm{B} 48$ action potentials (Rp-cAMP injected vs Rp-cAMP injected during superfusion of FCAP/CP2: $t=1.16, p=0.33, n=5$ ) (Fig. 7A3). This is in contrast with the increase in B48 firing that FCAP/CP2 produced in the absence of Rp-cAMP (Fig. 4).

Since the Rp-cAMP blocked the increase in the firing of $\mathrm{B} 48$ produced by exogenous application of FCAP/CP2, we reasoned that the effects of CBI-2 stimulation on the firing of B48 might also be eliminated by injection of Rp-cAMP. We tested this by measuring CBI-2 stimulation-induced changes in the number of B48 action potentials elicited by current injections. We found that in Rp-cAMPinjected B48 neurons stimulation of CBI-2 did not produce an increase in the number of action potentials (representative recording) (Fig. 7B2), an increase that otherwise was present in the absence of Rp-cAMP (Fig. 7B1). Statistical analysis of pre-CBI-2 Rp-cAMP-injected versus post-CBI-2 Rp-cAMP-injected B48 neurons showed that there was no difference between the two conditions $(t=1.97, p=$ $0.14, n=5)$. Therefore, cAMP appears to be necessary for the increase in the firing of B48 after CBI-2 stimulation.

\section{Motor programs: role of cAMP}

The previous experiments demonstrated the role of cAMP in increasing B48 firing but did not address the role cAMP may have during feeding motor programs. To gain further insight into whether the cAMP/PKA pathway was involved in repetition priming of B48 firing, we examined B48 activity during CBI-2-elicited feeding motor programs. In the first set of experiments, we elicited a series of motor programs using the L-ISI CBI-2 stimulation paradigm. Under these conditions, no buildup of ingestiveness occurs and motor programs remained intermediate as defined by the low firing frequency of $\mathrm{B} 8$ during both protraction and retraction phase. Here, after a series of L-ISI CBI-2 intermediate programs were elicited, 8-br-cAMP was iontophoretically injected into B48 for $15 \mathrm{~min}$. After the injection, a 
second series of L-ISI CBI-2 programs was elicited. We found that B8 firing frequency during both the protraction and retraction phases was unchanged, whereas the firing frequency of B48 during the protraction and post-retraction phases was selectivity increased during motor programs after injection (representative recording) (Fig. 8A). After a $20 \mathrm{~min}$ recovery period, B48 firing frequency returned to control intermediate levels.

After injections of B48 with 8-brcAMP, the L-ISI CBI-2-elicited programs remained intermediate as defined by the lack of phase specificity of B8 firing (aggregate data) (Fig. $8 B$ ). A one-way ANOVA revealed that the protractionphase and retraction-phase firing frequency of B8 did not significantly change from control, after B48 injection, or during programs elicited during the $20 \mathrm{~min}$ recovery (B8 protraction: $F_{(2,6)}=3.03$, $p=0.12, n=4$; B8 retraction: $F_{(2,6)}=$ $0.32, p=0.74, n=4)$.

Although the programs remained intermediate as defined by B8 activity, aggregate data showed a significant increase in B48 activity during the protraction and post-retraction phases (Fig. 8C). To determine the statistical significance of the differences among control, 8-br-cAMPinjected, and recovery groups, we performed a one-way ANOVA of B48 firing frequency in the protraction phase $\left(F_{(2,6)}=\right.$ 19.94, $p<0.05, n=4)$ and B48 firing frequency in the post-retraction phase $\left(F_{(2,6)}=12.19, p<0.05, n=4\right)$. Individual comparisons revealed that B48 fired significantly more after injection of 8-brcAMP than it did during the control or recovery period in both the protraction and post-retraction phases (protraction: control vs 8-br-cAMP injected: $t=5.77$, $p<0.05 ; 8$-br-cAMP injected vs recovery: $t=5.10, p<0.05$; post-retraction: control vs 8 -br-cAMP injected: $t=4.57, p<0.05,8$-br-cAMP injected vs recovery: $t=3.90, p<0.05$ ).

Further analysis of B48 activity during protraction phase revealed that the latency from the onset of CBI-2 stimulation to the first action potential in B48 decreased significantly after the injection of 8-br-cAMP $(t=4.42, p<0.05)$. Consistent with this observation, we found the fraction of the protraction phase in which B48 was active also increased after the injection of 8-br$\operatorname{cAMP}(t=11.6, p<0.05)$ (Fig. $8 D)$.

Together, the data shown in Figure 8 indicated that injection of 8-br-cAMP upregulated B48 activity during feeding motor programs. Thus, 8-br-cAMP mimicked the increase in B48 firing frequency observed during intermediate CBI-2 programs elicited in the presence of FCAP/CP2 (Fig. 2) and during repetitive S-ISI CBI-2-elicited programs (Friedman et al., 2009).

The experiment described above indicated that it was possible to mimic the effects of repeated S-ISI CBI-2 stimulation and peptide application on B48 with injection of 8-br-cAMP. How-
8-br-cAMP

L-ISI CBI-2 elicited program with 8-br-cAMP in B48

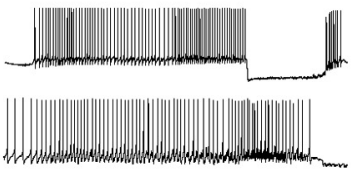

CBI-2 elicited

program after wash

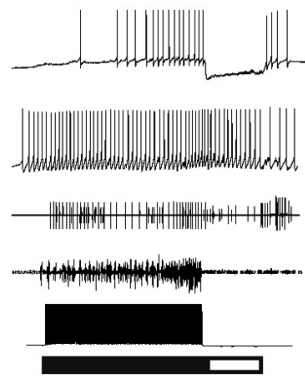

$5 s$

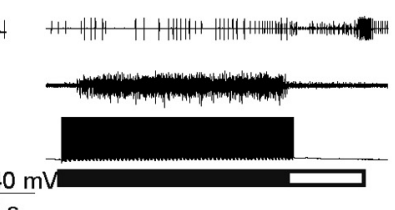

D
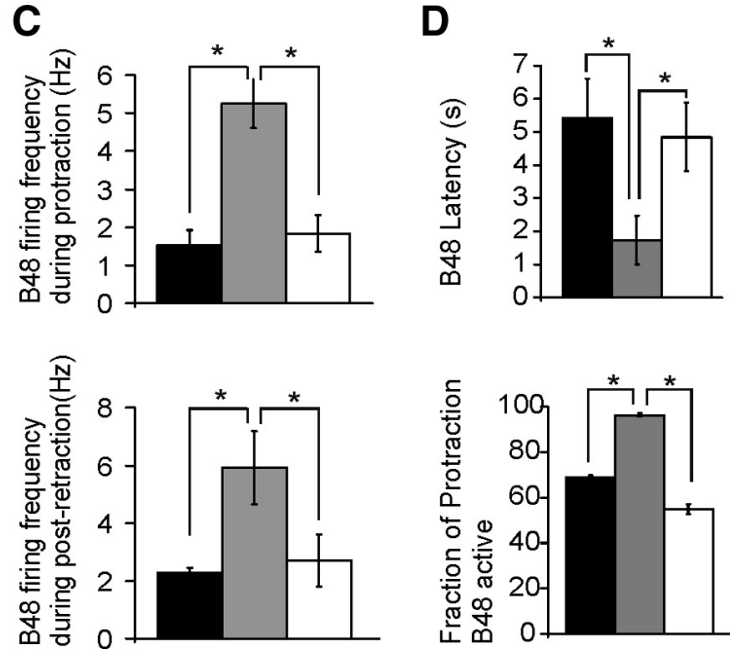

Figure 8. 8-br-cAMP mimics the effect of S-ISI repetitive CBI-2-elicited programs on B48 firing frequency. A series of five L-ISI program in which $B 48$ fired weakly in the protraction phase and $B 8$ fired weakly in both the protraction and retraction phases. After

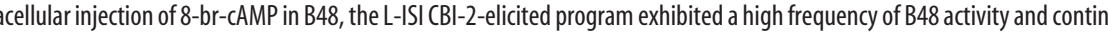
decreased to control levels. $B$. Aggregate data of the B48 protractan-phase and post-retraction-phase firing frequency during B from the start of $\mathrm{CBI}-2$ stimulation was reduced after 8-br-cAMP injection into B48. The fraction of protraction with B48 activity was higher after 8-br-cAMP injection compared with control and recovery.

ever, it was not evident whether this was the signaling pathway that was used during repetition priming of B48 during repetitive CBI-2 stimulation. The possibility remained that a different signaling pathway may be responsible for the increase in activity of B48 during feeding motor programs. We thus sought to determine whether cAMP/PKA was not only sufficient but was also necessary for the increased B48 firing that followed repetitive S-ISI CBI-2 stimulation.

In each preparation, we first elicited a series of $10 \mathrm{CBI}-2$ programs using an S-ISI (30 s) (Fig. 9A). This produced repetition priming, i.e., progressively more ingestive programs as defined by the significant increase of B8 retraction-phase activity (1st vs 10th: $t=5.68, p<0.05)$ and by the significant increase in B48 protraction-phase activity (1st vs 10th: $t=11.67, p<0.001$ ). After a $20 \mathrm{~min}$ recovery period, we initiated a $15 \mathrm{~min}$ iontophoretic injection of Rp-cAMP into B48. After the injection period, we again elicited a series of 10 S-ISI CBI-2 motor programs (Fig. 9B).

To determine the effects of the injections of Rp-cAMP into B48 on repetition priming, we compared the characteristics of 
A Control

First CBI-2

elicited program

B48

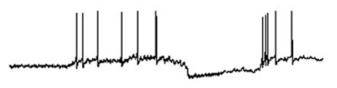

B8

$12 \mathrm{n}$

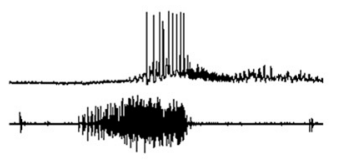

$\mathrm{CBI}-2$

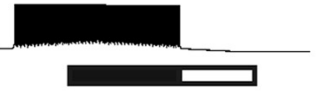

B

Rp-cAMP injected B48

First CBI-2

elicited program

B48

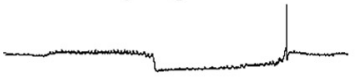

B8

$12 \mathrm{n}$

$\mathrm{CBI}-2$

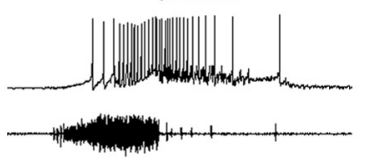

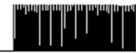

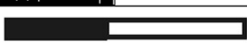

C

$\square$ Program 1

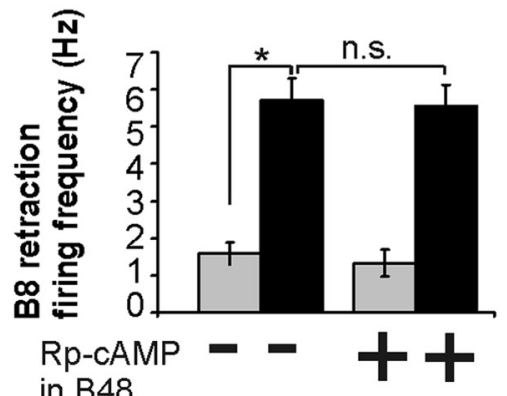

in B48

\section{Tenth CBI-2 elicited \\ ingestive program}
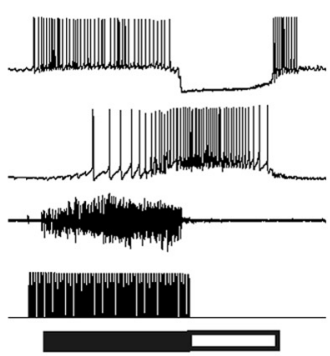

Tenth CBI-2-elicited program

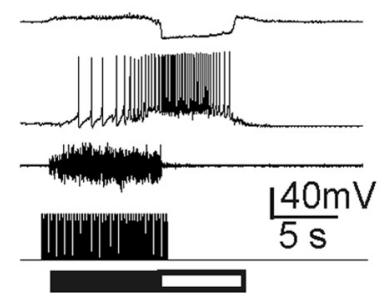

Program 10

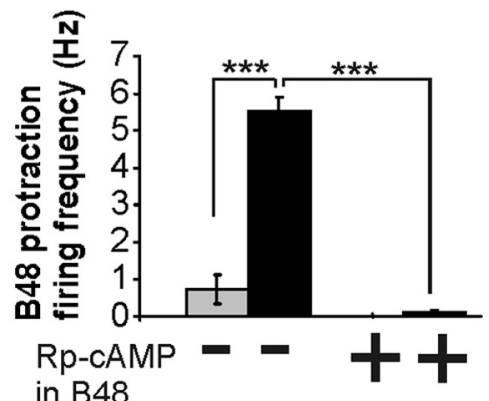

in B48

Figure 9. Effects of repetitive S-ISI CBI-2-elicited programs on B48 firing frequency are blocked by CAMP antagonist Rp-CAMP $A$, Control S-ISI CBI-2 programs illustrate the increase in B48 protraction and B8 retraction firing from the 1st to the 10th program. $B$, After injection of Rp-CAMP into B48, B48 protraction activity no longer increased from the 1st to the 10th S-ISI CBI-2-elicited program, while B8 retraction activity increased similar to the control. C, Average firing frequency from the 1st to 10th program of B48 protraction activity and B8 retraction activity.

S-ISI CBI-2 programs elicited before (control) and after RpcAMP injection into B48. First, a comparison of B8 retractionphase activity in the first programs in both series of stimulations (without and with Rp-cAMP) failed to reveal any differences between the two conditions $(t=2.46, p=0.10, n=4)$. The same was true for the 10th programs elicited in the two conditions $(t=$ $0.198, p=0.86, n=4$ ) (Fig. 9C). This indicated that, as defined by $\mathrm{B} 8$ activity, injections of Rp-cAMP into B48 had no effect on repetition priming of $\mathrm{B} 8$ firing. Next, we compared the effects of Rp-cAMP injection on the repetition priming of B48. In contrast to $\mathrm{B} 8$, we did not observe a progressive increase in $\mathrm{B} 48$ protraction-phase activity during the series of 10 programs. Comparison of B48 protraction-phase activity during the first program that was elicited in the absence Rp-cAMP and after its injection revealed no difference between the two conditions $(t=$ $1.92, p=0.15)$. In contrast, when the last programs were com- pared we found that there was significantly less B48-protraction-phase activity during the 10th program after Rp-cAMP injection $(t=14.44, p<0.001, n=4)$ than before Rp-cAMP injection. Thus, the increase in B48 firing frequency during repetitive $\mathrm{CBI}-2$ stimulation required $\mathrm{CAMP} / \mathrm{PKA}$ signaling. Therefore, c-AMP/PKA pathway appears to be critical for repetition priming of B48.

\section{Discussion}

Our data indicate that the repetition priming of $\mathrm{B} 48$ is mediated by two peptide cotransmitters of CBI-2, which act via cAMP/ PKA. cAMP/PKA activation increases the firing of B48. Consequently, when B48 receives an excitatory drive during motor programs, its firing increases.

\section{Motoneurons versus CPG}

Repetition priming, whereby pre-exposure to a stimulus enhances subsequent sensory, cognitive, and motor behaviors, operates in both vertebrates and invertebrates (Epuru et al., 1995; Schacter and Buckner, 1998; Sinnamon et al., 2000; Proekt and Weiss, 2003; Proekt et al., 2008). Despite the pervasiveness of repetition priming, surprisingly little is known about the cellular mechanisms that alter network dynamics to produce this phenomenon (Grill-Spector et al., 2006; Wig et al., 2009). Studies of repetition priming in the feeding network of Aplysia began to identify network-level mechanisms responsible for repetition priming.

In free-feeding Aplysia, a manifestation of food-stimulation-induced repetition priming is a progressive increase of radula movements (Weiss et al., 1982). In the nervous system, repetition priming is observed after stimulation of CBI-2 and is expressed as an increase in firing frequency of motoneurons B8 and B48. The relative phasing of the activity of these two motoneurons, as well as other motoneurons, is controlled by the CPG. Repetition priming of $\mathrm{B} 8$ activity is also controlled by the CPG and results from a change of balance of activity and synaptic efficacy of two CPG interneurons, B20 and B40, which promote egestive and ingestive motor programs, respectively (Jing and Weiss, 2001, 2002). Here, we obtain evidence that repetition priming of $B 48$ might involve modification of intrinsic characteristics of B48. Our experiments link repetition priming of B48 firing to the direct upmodulation of B48. Together with previous findings, current data indicate that in a CPG-controlled network repetition priming can be implemented both through CPG-dependent and CPG-independent processes.

\section{B48 versus $\mathrm{B} 8$}

CPG-dependent priming operates in the case of B8, and CPGindependent priming operates in the case of B48. Could these 
differences be related to the means that the CPG uses to drive these neurons and/or to their firing patterns? Studies in several systems show that there are different classes of motoneurons with different firing pattern characteristics (Morton and Chiel, 1993b; Jing and Weiss, 2001, 2005; d'Avella and Bizzi, 2005; Li et al., 2007). Here, B48 fires exclusively during protraction and only in CBI-2-elicited programs (Church and Lloyd, 1994; Evans et al., 1996). In contrast, B8 fires during retraction or protraction depending on the type of motor program (Morton and Chiel, 1993b; Nargeot et al., 1997). These differences are associated with two different modes with which the feeding CPG activates these motoneurons. $\mathrm{B} 8$ receives a balance of concurrent excitationinhibition from the CPG throughout protraction and retraction, which determines the phase in which B8 fires (Sasaki et al., 2009). The CPG controls B48 firing through alternating excitation-inhibition that occurs during protraction and retraction, respectively. In Figure 10, to simplify the hypothetical discussion of increased firing we use the concept of excitability. In Fig. 10, we illustrate the consequences of increasing the excitability of a neuron that, like B8, receives concurrent excitationinhibition. An increase of excitability of such a neuron would nonspecifically increase its firing. In the case of B8, this would result in radula closure during both protraction and retraction, thus producing a dysfunctional response. In contrast, an increase of excitability of a neuron that, like $\mathrm{B} 48$, receives alternating excitation and inhibition would result in more firing during protraction while remaining inhibited during retraction. In the case of B48, this would be appropriate for implementing stronger movements in a phase-specific manner.

The two modes of activating motoneurons, concurrent excitation-inhibition, and alternating excitation-inhibition (Fig. 10) have been identified as major modes of controlling network outputs in both vertebrates and invertebrates (Destexhe et al., 2003; Alaburda et al., 2005; Berg and Hounsgaard, 2009; Sasaki et al., 2009). Given that many networks are modulated, it should be possible to test the generality of the hypothesis that CPGdependent vs CPG-independent modulation may be preferentially used based on the type of inputs that motoneurons, or for that matter other network outputs, receive.

\section{Context versus experience}

Experience-dependent states (Abraham and Willows, 1971; Allport et al., 1994; Sharma et al., 2003; Proekt et al., 2004, 2008) are not the only types of states that can modify CPG outputs. CPG states, and therefore outputs, can be modified by the context in which responses are being elicited (Nolen and Hoy, 1984; Esch et al., 2002; Gold and Shadlen, 2003; Friesen and Kristan, 2007). Context-dependent and experience-dependent CPG states differ (Nadim et al., 2008). In context-dependent states, the activity of

\section{Alternating excitation/inhibition}

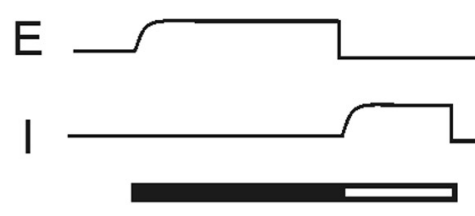

C1

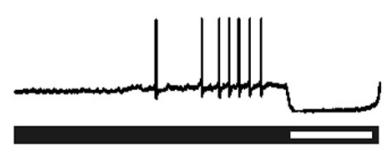

C2

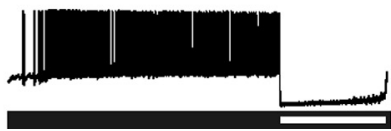

Figure 10. Effects of modulation of neuronal excitability differ depending on whether neurons are driven by concurrent

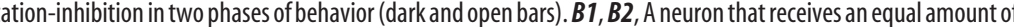
ults in its increased firing in both phases of behavior (B2) C1, A neuron that receives alternating excitation-inhibition has weak preference to fire in the phase during which it receives excitation. $\mathbf{C}$, An increase of the excitability of such a neuron selectively increases its firing in the phase during which it receives excitation.

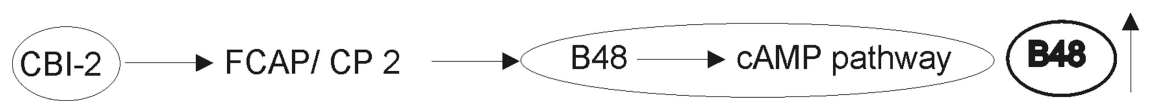

Figure 11. Hypothetical sequence underlying repetition priming of motoneuron B48 firing.

network elements can be controlled directly by the very hormones/modulators or modulatory networks that are part of the context. In contrast, to generate different responses experience-dependent states do not require the presence of modulators or activity of modulatory network inputs at the time when responses are generated. One cannot, however, assume that neuromodulators do not partake in establishing such experiencedependent states. The effects of neuromodulators are known to persist even when the neuromodulators are no longer present. Importantly, the presence of neuromodulators may be necessary for the acquisition but not for the subsequent expression of various forms of learning (Byrne and Kandel, 1996; Crow, 2004; Burrell and Sahley, 2005). Thus, at least in principle, neuromodulatory inputs may form a basis for transforming contextdependent network states into experience-dependent network states (Marder et al., 1996).

Our data indeed indicate that CBI-2, acting through its peptide cotransmitters, induces second messenger-mediated modulation of the intrinsic properties of B48 that persist when CBI-2 is no longer active (Fig. 11). As the effects of repeated CBI-2 stimulation can be blocked by Rp-cAMP and mimicked by 8 -BrcAMP, cAMP is sufficient and necessary for a priming of B48 activity. Second messengers are implicated in the regulation of several aspects of CPG outputs (Hempel et al., 1996; Heinrich et al., 2001; Katz and Clemens, 2001; Grillner, 2006; Doi and 
Ramirez, 2008). Importantly, our data suggest that second messengers are involved in the formation of persistent changes of the CPG output, and, intriguingly, they can do so by acting on specific motoneurons rather than via CPG. Our data thus support the idea that persistence of experience-dependent network states reflects the persistence of effects of neuromodulatory inputs.

\section{Feed-forward modulation}

When food contacts the mouth of Aplysia, CBI-2 receives an excitatory input that elicits CBI-2 firing (Rosen et al., 1991). CBI-2 stimulation produces feeding motor programs that correspond to feeding behaviors that CBI-2 elicits in semi-intact preparations (Morton and Chiel, 1993b; Morgan et al., 2002; Jing and Weiss, 2005). The mediating action of CBI-2 is implemented by fast synaptic actions of ACh, the primary transmitter of CBI-2. Our data indicate that CBI-2-induced priming of B48 firing is likely to involve FCAP and CP2 (Fig. 11). The combination of current and previous results indicates that CBI-2 acts both as a cholinergic initiator and a peptidergic neuromodulator of feeding responses.

A similar duality of function exists in buccal motoneurons. Many buccal motoneurons use their primary transmitter to initiate/mediate buccal muscle contractions (Cohen et al., 1978; Church and Lloyd, 1994) and use their neuropeptides to upmodulate muscle contractions (Lloyd et al., 1984; Cropper et al., 1987; Lotshaw and Lloyd, 1990; Evans et al., 1999; Hurwitz et al., 2000). CBI-2-dependent upmodulation of motoneuronal firing and CPG-independent upmodulation of muscle contractions represent a feed-forward modulation. This has important consequences. First, the CBI-2-dependent increase of motoneuronal firing will result in larger muscle contractions (Cohen et al., 1978; Evans et al., 1996; Brezina et al., 2000a). Second, since greater amounts of peptides are released when motoneurons fire at higher frequencies (Vilim et al., 1996a,b), the increased firing of motoneurons will produce a greater upmodulation of muscle contractions. The dual effects of upmodulation of motoneuronal firing may provide an elegant mechanism for amplifying the neuromodulatory actions of CBI-2.

The effects of feed-forward modulation need not be limited to muscles and may be present in the nervous system. For instance, a chain of three neurons in which neuron 1 upmodulates neuron 2, and neuron 2 both upmodulates and elicits fast EPSPs in neuron 3 could produce similar amplifying effects on the firing of neuron 3 as those described for muscle contractions. Although feed-forward excitation and inhibition involving fast synaptic actions have been described in a number of networks, there appear to be no explicit descriptions of feed-forward modulation. Considering that invertebrate and vertebrate CPGs share a number of organizational motifs, feed-forward modulation may emerge as a motif in the organization of vertebrate networks.

\section{Summary}

Briefly, our study indicates that, acting via cAMP, peptidergic inputs to motor networks play an important role in inducing persistent experience-dependent network states that manifest themselves as repetition priming. Importantly, this study also suggests that in CPG-driven motor networks modulation of intrinsic motoneuronal characteristics may be used to generate persistent changes of network outputs. We suggest that utilization of CPG-dependent versus CPG-independent plasticity may be linked to whether a given motoneuron is driven by concurrent versus alternating excitation-inhibition, respectively.

\section{References}

Abraham FD, Willows AOD (1971) Plasticity of a fixed action pattern in the sea slug Tritonia diomedia. Commun Behav Biol 6:271-280.

Alaburda A, Russo R, MacAulay N, Hounsgaard J (2005) Periodic highconductance states in spinal neurons during scratch-like network activity in adult turtles. J Neurosci 25:6316-6321.

Allport D, Styles E, Hsieh S (1994) Shifting intentional set: exploring the dynamic control of tasks. In: Attention and performance (Moscovitch CUaM, ed), pp 421-452. Cambridge, MA: MIT.

Berg R, Hounsgaard J (2009) Signaling in large-scale neural networks. Cogn Process 10:9-15.

Brezina V, Orekhova IV, Weiss KR (2000a) The neuromuscular transform: the dynamic, nonlinear link between motor neuron firing patterns and muscle contraction in rhythmic behaviors. J Neurophysiol 83:207-231.

Brezina V, Church PJ, Weiss KR (2000b) Temporal pattern dependence of neuronal peptide transmitter release: models and experiments. J Neurosci 20:6760-6772.

Burrell BD, Sahley CL (2005) Serotonin mediates learning-induced potentiation of excitability. J Neurophysiol 94:4002-4010.

Byrne JH, Kandel ER (1996) Presynaptic facilitation revisited: state and time dependence. J Neurosci 16:425-435.

Calabrese RL (1998) Cellular, synaptic, network, and modulatory mechanisms involved in rhythm generation. Curr Opin Neurobiol 8:710-717.

Church PJ, Lloyd PE (1994) Activity of multiple identified motor neurons recorded intracellularly during evoked feedinglike motor programs in Aplysia. J Neurophysiol 72:1794-1809.

Cohen JL, Weiss KR, Kupfermann I (1978) Motor control of buccal muscles in Aplysia. J Neurophysiol 41:157-180.

Cropper EC, Tenenbaum R, Kolks MA, Kupfermann I, Weiss KR (1987) Myomodulin: a bioactive neuropeptide present in an identified cholinergic buccal motor neuron of Aplysia. Proc Natl Acad Sci US A 84:5483-5486.

Cropper EC, Price D, Tenenbaum R, Kupfermann I, Weiss KR (1990) Release of peptide cotransmitters from a cholinergic motor neuron under physiological conditions. Proc Natl Acad Sci U S A 87:933-937.

Cropper EC, Evans CG, Hurwitz I, Jing J, Proekt A, Romero A, Rosen SC (2004) Feeding neural networks in the mollusc Aplysia. Neurosignals $13: 70-86$.

Crow T (2004) Pavlovian conditioning of Hermissenda: current cellular, molecular, and circuit perspectives. Learn Mem 11:229-238.

d'Avella A, Bizzi E (2005) Shared and specific muscle synergies in natural motor behaviors. Proc Natl Acad Sci U S A 102:3076-3081.

Destexhe A, Rudolph M, Paré D (2003) The high-conductance state of neocortical neurons in vivo. Nat Rev Neurosci 4:739-751.

Dickinson PS (2006) Neuromodulation of central pattern generators in invertebrates and vertebrates. Curr Opin Neurobiol 16:604-614.

Doi A, Ramirez JM (2008) Neuromodulation and the orchestration of the respiratory rhythm. Respir Physiol Neurobiol 164:96-104.

Epuru DR, Liang HH, Sinnamon HM (1995) Neural activity in the midbrain correlated with hindlimb extension initiated by locomotor stimulation of the hypothalamus of the anesthetized rat. Neuroscience 64:507-524.

Esch T, Mesce KA, Kristan WB (2002) Evidence for sequential decision making in the medicinal leech. J Neurosci 22:11045-11054.

Evans CG, Rosen S, Kupfermann I, Weiss KR, Cropper EC (1996) Characterization of a radula opener neuromuscular system in Aplysia. J Neurophysiol 76:1267-1281.

Evans CG, Vilim FS, Harish O, Kupfermann I, Weiss KR, Cropper EC (1999) Modulation of radula opener muscles in Aplysia. J Neurophysiol 82:1339-1351.

Friedman AK, Zhurov Y, Ludwar BCh, Weiss KR (2009) Motor outputs in a multitasking network: relative contributions of inputs and experiencedependent network states. J Neurophysiol 102:3711-3727.

Friesen WO, Kristan WB (2007) Leech locomotion: swimming, crawling, and decisions. Curr Opin Neurobiol 17:704-711.

Ghirardi M, Braha O, Hochner B, Montarolo PG, Kandel ER, Dale N (1992) Roles of PKA and PKC in facilitation of evoked and spontaneous transmitter release at depressed and nondepressed synapses in Aplysia sensory neurons. Neuron 9:479-489.

Gold JI, Shadlen MN (2003) The influence of behavioral context on the representation of a perceptual decision in developing oculomotor commands. J Neurosci 23:632-651.

Goldsmith BA, Abrams TW (1992) cAMP modulates multiple K+ currents, 
increasing spike duration and excitability in Aplysia sensory neurons. Proc Natl Acad Sci U S A 89:11481-11485.

Grillner S (2006) Biological pattern generation: the cellular and computational logic of networks in motion. Neuron 52:751-766.

Grill-Spector K, Henson R, Martin A (2006) Repetition and the brain: neural models of stimulus-specific effects. Trends Cogn Sci 10:14-23.

Harris-Warrick RM, Marder E (1991) Modulation of neural networks for behavior. Annu Rev Neurosci 14:39-57.

Heinrich R, Wenzel B, Elsner N (2001) A role for muscarinic excitation: control of specific singing behavior by activation of the adenylate cyclase pathway in the brain of grasshoppers. Proc Natl Acad Sci U S A 98:9919-9923.

Hempel CM, Vincent P, Adams SR, Tsien RY, Selverston AI (1996) Spatiotemporal dynamics of cyclic AMP signals in an intact neural circuit. Nature 384:166-169.

Hurwitz I, Susswein AJ (1996) B64, a newly identified central pattern generator element producing a phase switch from protraction to retraction in buccal motor programs of Aplysia californica. J Neurophysiol 75:13271344.

Hurwitz I, Neustadter D, Morton DW, Chiel HJ, Susswein AJ (1996) Activity patterns of the B31/B32 pattern initiators innervating the I2 muscle of the buccal mass during normal feeding movements in Aplysia californica. J Neurophysiol 75:1309-1326.

Hurwitz I, Kupfermann I, Susswein AJ (1997) Different roles of neurons B63 and B34 that are active during the protraction phase of buccal motor programs in Aplysia californica. J Neurophysiol 78:1305-1319.

Hurwitz I, Cropper EC, Vilim FS, Alexeeva V, Susswein AJ, Kupfermann I, Weiss KR (2000) Serotonergic and peptidergic modulation of the buccal mass protractor muscle (I2) in Aplysia. J Neurophysiol 84:2810-2820.

Hurwitz I, Kupfermann I, Weiss KR (2003) fast synaptic connections from CBIs to pattern-generating neurons in Aplysia: initiation and modification of motor programs. J Neurophysiol 89:2120-2136.

Jing J, Weiss KR (2001) Neural mechanisms of motor program switching in Aplysia. J Neurosci 21:7349-7362.

Jing J, Weiss KR (2002) Interneuronal basis of the generation of related but distinct motor programs in Aplysia: implications for current neuronal models of vertebrate intralimb coordination. J Neurosci 22:6228-6238.

Jing J, Weiss KR (2005) Generation of variants of a motor act in a modular and hierarchical motor network. Curr Biol 15:1712-1721.

Jing J, Vilim FS, Wu JS, Park JH, Weiss KR (2003) Concerted GABAergic actions of Aplysia feeding interneurons in motor program specification. J Neurosci 23:5283-5294.

Jing J, Vilim FS, Horn CC, Alexeeva V, Hatcher NG, Sasaki K, Yashina I, Zhurov Y, Kupfermann I, Sweedler JV, Weiss KR (2007) From hunger to satiety: reconfiguration of a feeding network by Aplysia neuropeptide Y. J Neurosci 27:3490-3502.

Kabotyanski EA, Baxter DA, Byrne JH (1998) Identification and characterization of catecholaminergic neuron B65, which initiates and modifies patterned activity in the buccal ganglia of Aplysia. J Neurophysiol 79:605-621.

Katz PS, Clemens S (2001) Biochemical networks in nervous systems: expanding neuronal information capacity beyond voltage signals. Trends Neurosci 24:18-25.

Klein M, Hochner B, Kandel ER (1986) Facilitatory transmitters and cAMP can modulate accommodation as well as transmitter release in Aplysia sensory neurons: evidence for parallel processing in a single cell. Proc Natl Acad Sci U S A 83:7994-7998.

Koh HY, Weiss KR (2005) Peptidergic contribution to posttetanic potentiation at a central synapse of Aplysia. J Neurophysiol 94:1281-1286.

Koh HY, Weiss KR (2007) Activity-dependent peptidergic modulation of the plateau-generating neuron B64 in the feeding network of Aplysia. J Neurophysiol 97:1862-1867.

Koh HY, Vilim FS, Jing J, Weiss KR (2003) Two neuropeptides colocalized in a command-like neuron use distinct mechanisms to enhance its fast synaptic connection. J Neurophysiol 90:2074-2079.

Kupfermann I (1974) Feeding behavior in Aplysia: a simple system for the study of motivation. Behav Biol 10:1-26.

Li WC, Sautois B, Roberts A, Soffe SR (2007) Reconfiguration of a vertebrate motor network: specific neuron recruitment and context-dependent synaptic plasticity. J Neurosci 27:12267-12276.

Lloyd PE, Kupfermann I, Weiss KR (1984) Evidence for parallel actions of a molluscan neuropeptide and serotonin in mediating arousal in Aplysia. Proc Natl Acad Sci U S A 81:2934-2937.

Lotshaw DP, Lloyd PE (1990) Peptidergic and serotonergic facilitation of a neuromuscular synapse in Aplysia. Brain Res 526:81-94.

Lum CS, Zhurov Y, Cropper EC, Weiss KR, Brezina V (2005) Variability of swallowing performance in intact, freely feeding Aplysia. J Neurophysiol 94:2427-2446.

Marder E, Thirumalai V (2002) Cellular, synaptic and network effects of neuromodulation. Neural Netw 15:479-493.

Marder E, Abbott LF, Turrigiano GG, Liu Z, Golowasch J (1996) Memory from the dynamics of intrinsic membrane currents. Proc Natl Acad Sci U S A 93:13481-13486.

Morgan PT, Perrins R, Lloyd PE, Weiss KR (2000) Intrinsic and extrinsic modulation of a single central pattern generating circuit. J Neurophysiol 84:1186-1193.

Morgan PT, Jing J, Vilim FS, Weiss KR (2002) Interneuronal and peptidergic control of motor pattern switching in Aplysia. J Neurophysiol 87:49-61.

Morton DW, Chiel HJ (1993a) In vivo buccal nerve activity that distinguishes ingestion from rejection can be used to predict behavioral transitions in Aplysia. J Comp Physiol A 172:17-32.

Morton DW, Chiel HJ (1993b) The timing of activity in motor neurons that produce radula movements distinguishes ingestion from rejection in Aplysia. J Comp Physiol A 173:519-536.

Nadim F, Brezina V, Destexhe A, Linster C (2008) State dependence of network output: modeling and experiments. J Neurosci 28:11806-11813.

Nargeot R, Baxter DA, Byrne JH (1997) Contingent-dependent enhancement of rhythmic motor patterns: an in vitro analog of operant conditioning. J Neurosci 17:8093-8105.

Nargeot R, Baxter DA, Byrne JH (1999a) In vitro analog of operant conditioning in Aplysia. I. Contingent reinforcement modifies the functional dynamics of an identified neuron. J Neurosci 19:2247-2260.

Nargeot R, Baxter DA, Byrne JH (1999b) In vitro analog of operant conditioning in Aplysia. II. Modifications of the functional dynamics of an identified neuron contribute to motor pattern selection. J Neurosci 19:2261-2272.

Nolen TG, Hoy RR (1984) Initiation of behavior by single neurons: the role of behavioral context. Science 226:992-994.

Orekhova IV, Jing J, Brezina V, DiCaprio RA, Weiss KR, Cropper EC (2001) Sonometric measurements of motor-neuron-evoked movements of an internal feeding structure (the radula) in Aplysia. J Neurophysiol 86:1057-1061.

Phares GA, Walent JH, Niece RL, Kumar SB, Ericsson LH, Kowalak JA, Lloyd PE (1996) Primary structure of a new neuropeptide, cerebral peptide 2, purified from cerebral ganglia of Aplysia. Biochemistry 35:5921-5927.

Proekt A, Weiss KR (2003) convergent mechanisms mediate preparatory states and repetition priming in the feeding network of Aplysia. J Neurosci 23:4029-4033.

Proekt A, Brezina V, Weiss KR (2004) Dynamical basis of intentions and expectations in a simple neuronal network. Proc Natl Acad Sci U S A 101:9447-9452.

Proekt A, Jing J, Weiss KR (2007) multiple contributions of an inputrepresenting neuron to the dynamics of the Aplysia feeding network. J Neurophysiol 97:3046-3056.

Proekt A, Wong J, Zhurov Y, Kozlova N, Weiss KR, Brezina V (2008) Predicting adaptive behavior in the environment from central nervous system dynamics. PLoS One 3:e3678.

Rosen SC, Teyke T, Miller MW, Weiss KR, Kupfermann I (1991) Identification and characterization of cerebral-to-buccal interneurons implicated in the control of motor programs associated with feeding in Aplysia. J Neurosci 11:3630-3655.

Sasaki K, Due MR, Jing J, Weiss KR (2007) Feeding CPG in Aplysia directly controls two distinct outputs of a compartmentalized interneuron that functions as a CPG element. J Neurophysiol 98:3796-3801.

Sasaki K, Jing J, Due MR, Weiss KR (2008) An input-representing interneuron regulates spike timing and thereby phase switching in a motor network. J Neurosci 28:1916-1928.

Sasaki K, Brezina V, Weiss KR, Jing J (2009) Distinct inhibitory neurons exert temporally specific control over activity of a motoneuron receiving concurrent excitation and inhibition. J Neurosci 29:11732-11744.

Schacter DL, Buckner RL (1998) Priming and the brain. Neuron 20:185-195. 
Sharma J, Dragoi V, Tenenbaum JB, Miller EK, Sur M (2003) V1 neurons signal acquisition of an internal representation of stimulus location. Science 300:1758-1763.

Sinnamon HM, Jassen AK, Vita LA (2000) Brainstem regions with neuronal activity patterns correlated with priming of locomotor stepping in the anesthetized rat. Neuroscience 99:77-91.

Susswein AJ, Byrne JH (1988) Identification and characterization of neurons initiating patterned neural activity in the buccal ganglia of Aplysia. J Neurosci 8:2049-2061.

Sweedler JV, Li L, Rubakhin SS, Alexeeva V, Dembrow NC, Dowling O, Jing J, Weiss KR, Vilim FS (2002) Identification and characterization of the feeding circuit-activating peptides, a novel neuropeptide family of Aplysia. J Neurosci 22:7797-7808.

Swensen AM, Marder E (2000) Multiple peptides converge to activate the same voltage-dependent current in a central pattern-generating circuit. J Neurosci 20:6752-6759.

Teyke T, Rosen SC, Weiss KR, Kupfermann I (1993) Dopaminergic neuron B20 generates rhythmic neuronal activity in the feeding motor circuitry of Aplysia. Brain Res 630:226-237.

Trudeau LE, Castellucci VF (1992) Contribution of polysynaptic pathways in the mediation and plasticity of Aplysia gill and siphon withdrawal reflex: evidence for differential modulation. J Neurosci 12:3838-3848.

Vilim FS, Price DA, Lesser W, Kupfermann I, Weiss KR (1996a) Costorage and corelease of modulatory peptide cotransmitters with partially antagonistic actions on the accessory radula closer muscle of Aplysia californica. J Neurosci 16:8092-8104.

Vilim FS, Cropper EC, Price DA, Kupfermann I, Weiss KR (1996b) Release of peptide cotransmitters in Aplysia: regulation and functional implications. J Neurosci 16:8105-8114.

Vilim FS, Cropper EC, Price DA, Kupfermann I, Weiss KR (2000) Peptide cotransmitter release from motorneuron B16 in Aplysia californica: costorage, corelease, and functional implications. J Neurosci 20:2036-2042.

Vilim FS, Alexeeva V, Moroz LL, Li L, Moroz TP, Sweedler JV, Weiss KR (2001) Cloning, expression and processing of the CP2 neuropeptide precursor of Aplysia. Peptides 22:2027-2038.

Vilim FS, Sasaki K, Rybak J, Alexeeva V, Cropper EC, Jing J, Orekhova IV, Brezina V, Price D, Romanova EV, Rubakhin SS, Hatcher N, Sweedler JV, Weiss KR (2010) Distinct mechanisms produce functionally complementary actions of neuropeptides that are structurally related but derived from different precursors. J Neurosci 30:131-147.

Weiss K, Koch U, Koester J, Rosen S, Kupfermann I (1982) The role of arousal in modulating feeding behavior of Aplysia: neural and behavioral studies. In: The neural basis of feeding and reward (Hoebel BG, Novin D, eds). Brunswick, ME: Haer Institute.

Whim MD, Lloyd PE (1989) Frequency-dependent release of peptide cotransmitters from identified cholinergic motor neurons in Aplysia. Proc Natl Acad Sci U S A 86:9034-9038.

Whim MD, Lloyd PE (1990) Neuropeptide cotransmitters released from an identified cholinergic motor neuron modulate neuromuscular efficacy in Aplysia. J Neurosci 10:3313-3322.

Wig GS, Buckner RL, Schacter DL (2009) Repetition priming influences distinct brain systems: evidence from task-evoked data and resting-state correlations. J Neurophysiol 101:2632-2648.

Wu JS, Due MR, Sasaki K, Proekt A, Jing J, Weiss KR (2007) State dependence of spike timing and neuronal function in a motor pattern generating network. J Neurosci 27:10818-10831.

Zhurov Y, Proekt A, Weiss KR, Brezina V (2005) Changes of internal state are expressed in coherent shifts of neuromuscular activity in Aplysia feeding behavior. J Neurosci 25:1268-1280. 